\title{
The Study of Internet Learning Constructed by Network Live Education System
}

\author{
Yang Jing \\ Hubei University of Police, Wuhan, 430034, China
}

Keywords: webcast; Internet of things; online education; learning ecology; interactive teaching.

\begin{abstract}
With the hot online education, people pay more and more attention to the convenience and efficiency of the network classroom. It has become a major trend for online education in the development of education industry in the future. So it is necessary to meet the needs of online education for more people and build a network live online education system under the environment of Internet. A good learning environment shall be created so that teachers can teach online classes through these resources. This study analyzes and summarizes the present situation of the live learning of college students under the Internet + environment, and discusses two schemes of video audio and whiteboard interactive teaching in the network, and finally puts forward some suggestions on the ecological development of network live learning under the environment of the Internet. It has a certain significance for the development of modern network education.
\end{abstract}

\section{Introduction}

The ecological classroom under the Internet environment can fully link the schools, teachers, students and parents together to form an organic closed loop, an organic ecology, presenting positive or negative classes in the classroom teaching organized by the school. This important part is the teacher, in the present education reform. In the background, teachers are implementers and participants. Teachers can only understand scientifically the ecological classroom, and people oriented teachers may have a definite purpose. Also in the Internet + environment, the ecological research of the network live classroom is also very important. At present, the network live classroom is mainly divided into video audio teaching and whiteboard teaching. The combination of these two teaching methods can increase the real time and interaction of the webcast classroom, improve the video audio and whiteboard Teaching technology level. Improving the level of teachers in webcast teaching is of great significance to the ecological development of webcast classroom.

\section{The current situation of live learning of College Students under the Internet + Environment}

In order to understand the present situation of College Students' live learning, through the form of literature survey and data statistics, this paper makes a survey of students' understanding of live broadcast, the viewing frequency of live broadcast, the teachers' power of platform and the payment of the platform, and the following four aspects are introduced.

\subsection{College students' understanding of live broadcast.}

According to the survey, the students' understanding of the learning platform is counted, among which the first is the fight fish platform, the YY live platform is second, the third is the most recently very hot B station, the panda TV and the live broadcast are fourth and fifth respectively, and there are many other platforms. For students, the attention of the live learning platform is relatively high, and gradually began to contact and use live learning platform.

\subsection{The frequency of college students watching live broadcast.}

Although the live platform is hot, but the students who often use live platform only about $10 \%$, about $50 \%$ of the students occasionally look at the learning platform live, $30 \%$ of the students do not look live, and a few students have almost never seen live. 


\subsection{The situation of the platform for teachers.}

The teacher is the key of the direct seeding platform, but the teacher is the key to the live platform. The teaching level and the quality of the teacher directly affect the students' learning whether they can reach the expected value and whether they are interested in the course. Therefore, the direct seeding platform must pay attention to the construction of the teachers' team in the process of development. Gather some excellent teachers and curriculum development teams to provide quality service resources for students of online live learning, thereby enhancing the credibility of the platform.

\subsection{Analysis of platform payment.}

From the charge of live platform, most of the domestic are the platform of charge, and there are a few free platforms. The pay platform generally provides free trial, the teacher of the lecture is better, the teacher has some experience and fame. The free platform can generally watch video directly. Compared with the toll platform, its reputation and the quality of the course are a little lower. The teaching content is generally relatively basic, not a very systematic teaching content.

\section{Construction of network live learning platform under Internet + Environment}

There are two kinds of network live learning platform in the Internet + environment. One is interactive teaching of audio and video, the other is whiteboard interactive teaching. Using Internet + technology can build multi channel video low delay interactive live broadcast system. In the process of direct live teaching, live video, teaching and chat text and documents and so on It can be mixed and superimposed, and then mixed into single path output, which can effectively reduce the cost of bandwidth and also achieve high quality courseware recording. The basic framework is shown in Figure 1.

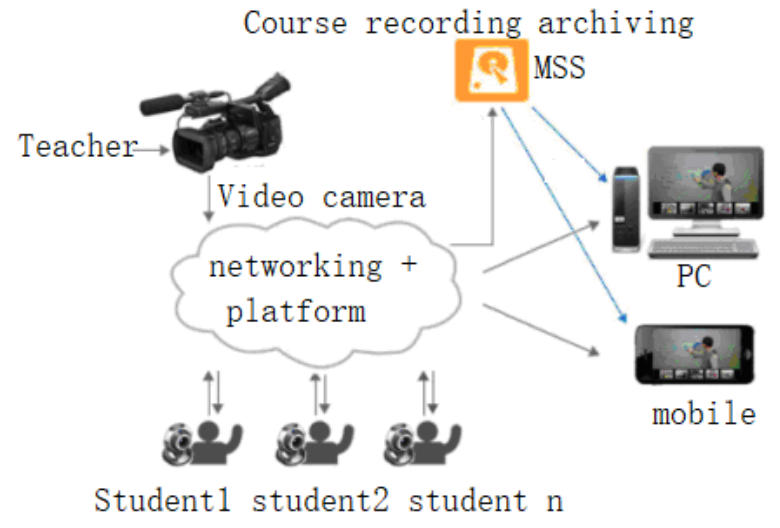

Fig.1 The framework for audio and video live learning platform

As shown in Figure 1, using audio and video broadcast learning platform, the interaction between teachers and students can be realized under low time delay. A large number of widths can be saved by mixing single path output. Video and live interactive programs can be played simultaneously, and the effect of barrage, text and video can be used to increase the effect of teaching. Vividness and richness. Another way of direct live teaching under the Internet + environment is the whiteboard interactive teaching scheme, its basic framework is shown in Figure 2.

Whiteboard interactive teaching is more interactive than video audio interactive teaching. White board interactive service system can be used to send whiteboard to teachers and many users. Whiteboard content includes teaching courseware and various documents and so on. It can be written and painted on the document. It improves the interaction of teaching process. 


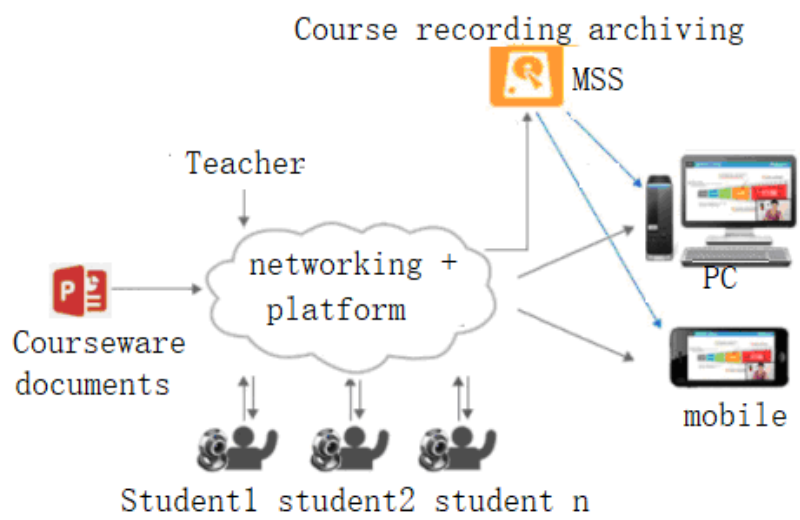

Fig.2 The basic theoretical framework for interactive teaching of Whiteboard

\section{Suggestions on the development of weblive learning platform under the Internet + Environment}

Under the Internet + environment, the following suggestions are put forward in order to improve the quality and the level of the platform construction, strengthen the development of the learning system, and build the integrity of the teaching, learning, feedback, evaluation and summary according to the use of the weblive platform and the construction of the live platform. The standardization of the learning system to realize the personalized ecological classroom under the Internet + environment.

\subsection{The APP of learning resources.}

The APP of learning resources is the important content of constructing the Internet + learning platform. Using APP can be the sharing of the resources of e-books. It can also communicate and interact, realize the innovation of learning mode. On the other hand, the learning process feedback can be realized by using APP, so that the platform can grasp the students' learning situation in a timely manner. In the process of APP development, in order to classify different functions, we can develop multiple APP terminals, and make use of APP combination scheme to fully realize online live online teaching.

\subsection{The interactive learning scheme based on intelligent mobile terminal.}

The learning scheme based on mobile intelligent terminal is an important function to realize the direct live learning and interaction and interaction of the Internet + environment network. It can adopt various forms of APP combination to support the students' learning process in an all-round way, select multiple APP for combination and improve the learning efficiency.

\subsection{The interactive learning program for the learning process.}

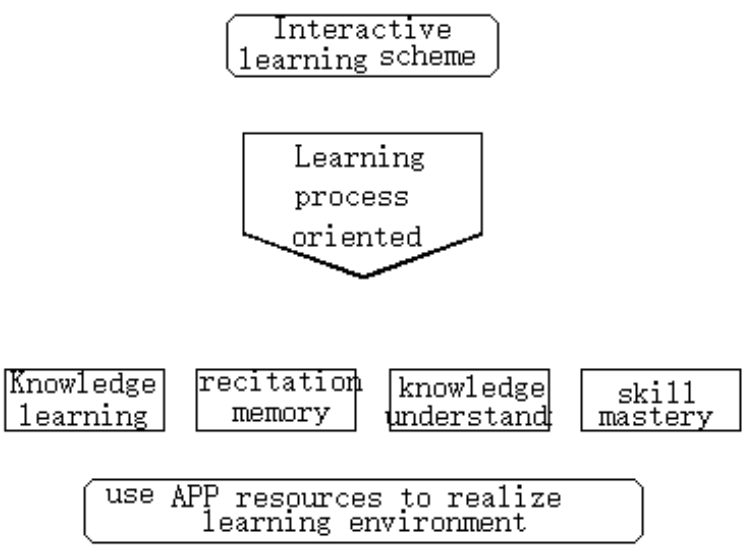

Fig.3 The interactive learning ecology oriented to the learning process 
The interactive program for the learning process is also a strategy to improve the learning efficiency of the webcast platform under the Internet + learning environment. The basic framework is shown in Figure 3.

As shown in Figure 3, in the Internet + environment, an interactive learning scheme can be used to communicate and interact with knowledge learning, reciting memory, understanding application and knowledge skills based on the learning process, and using APP to interact learning resources to realize the innovation of each ring in the learning process.

\section{Conclusion}

In order to study the Internet + learning ecology built on the Internet, this paper makes an investigation and Analysis on the use of Internet direct seeding for college students under the Internet + environment, and carries out the data integration of the students' understanding of the live broadcast, the frequency of the students watching live broadcast, the situation of the platform teachers and the platform payment. Plan. Two kinds of classroom forms are analyzed, one is the form of live video audio class, the other is whiteboard style teaching. The two kinds of network live classes have strong interaction, which is of great significance to the realization of the ecological classroom. Finally, it puts forward some suggestions on the ecological development of web-based classroom, hoping to provide some reference for the development of modern network education.

\section{Acknowledgement}

The work was supported by the two projects. One is from the annual general topics of Education Science Planning in Hubei Province with the project number 2017GB050 and the project name The study of "Internet + " learning ecology constructed by network direct seeding. The other is from the electronic forensics and trusted application 2018 innovation team of Hubei Collaborative Innovation Center with the project number 2018XTCX22C with its name Password cracking software research team.

\section{References}

[1] Liu Mengchao, Xiao Jirong, Chen Rong. Application of data mining in user behavior analysis[J]. Computer knowledge and technology, 2012, 31 (04): 7409-7412。

[2] Feng Wenbo, Luo Wei Liang. Research on the "technology art" training system of digital media arts [J]. modern decoration (Theory), 2011,33 (06): 75-76.

[3] Liu Juemin. On the training of digital media arts professionals [J]. mass media, 2012,29 (20): 265-266.

[4] Jing Yu. From the development of digital media (Art / Technology) to digital media[J]. law education research in China is explored, 2012,11 (01): 150-165

[5] Li Aijuan. The guiding role of constructivist learning theory in courseware development [J]. teaching and management: theoretical version, 2007, (11): 68-69.

[6] Chen Li. Distance learning interaction model and teaching interaction level [J]. Chinese distance education.2004, (5): 24-28.

[7] Pan Feng Nan. Analysis and Research on user behavior of campus network [J]. Journal of Yangtze University, 2013, 23 (02): 1403-1409.

[8] Li Changxian. Research on school users' network behavior classification system [J]. statistics and management, 2013, 04 (61):144-145.

[9] Zhang Jinliang, Ho tall. Learning analysis: boosting the online professional development of university teachers in the era of big data [J]. Journal of distance education, 2014, (2): 56-62. 
[10] Jiang Qiang, Zhao Yu, Wang Pengjiao. An adaptive learning system architecture based on GALSRM model [J]. modern distance education, 2013, (1): 71-77.

[11] Zou Shen. Corpus based research on validity of writing test: Taking English writing teaching corpus as an example, [J]. foreign language audio-visual instruction, 2012, (1): 16-21.

[12] Zhu Xiaohui. The study of language transfer in third language acquisition and the enlightenment to the teaching of double foreign language major [J]. Journal of Guangdong University of Foreign Studies, 2008, (5): 109-112.

[13] Chen Baopeng, Hu Ailing. Analysis of the stratified teaching mode in the popularization stage of higher education [J]. Journal of Liaoning radio and TV University, 2009, (2): 51- 52.

[14] Yang Yang. On the advantages and disadvantages of multimedia teaching in English teaching [J]. Journal of Jilin radio and TV University, 2011 (6): 146-147.

[15] Zhang Yan Hong. A dynamic assessment model of College English online writing teaching [J]. foreign language community, 2008, (4): 73-81.

[16] Wang Xiaoqin. Theory and practice of hierarchical teaching mode of higher mathematics [J]. Jilin education, 2009, (11): 20- 21.

[17] Mao Dahui. Implementation of hierarchical teaching in Higher Vocational Mathematics [J]. Journal of Chongqing Vocational and Technical College, 2007,16 (4): $43-44$.

[18] Jiang Qiang, Zhao Yu. The design and implementation of an adaptive learning system for the perspective of "service" [J]. audio-visual education in China, 2011, (2): 119-124.

[19] Li Yanyan, Ma Shaoqian, Huang Ronghuai. Learning analysis technology: service learning process design and optimization of [J]. open education research, 2012, (5): 18-24. 